\title{
Assessment of Hepatic Steatosis in Living Donor Liver Transplantation: Comparison Between IDEAL MRI and CT
}

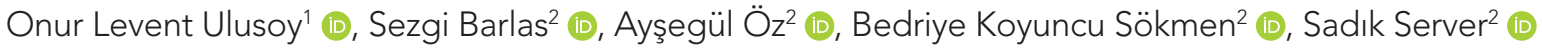 \\ ${ }^{1}$ Clinic of Radiology, İstanbul Florence Nightingale Hospital, İstanbul, Turkey \\ ${ }^{2}$ Department of Radiology, İstanbul Bilim University School of Medicine, İstanbul, Turkey \\ Cite this article as: Ulusoy OL, Barlas S, Öz A, Koyuncu Sökmen B, Server S. Assessment of Hepatic Steatosis in Living Donor Liver \\ Transplantation: Comparison Between IDEAL MRI and CT. JAREM 2018; 8(3): 182-5.
}

\begin{abstract}
Objective: To evaluate and compare the diagnostic accuracy of Iterative Decomposition of Water and Fat with Echo Asymmetry and Least Squares Estimation (IDEAL) Magnetic Resonance Imaging (MRI) sequence with Computed Tomography (CT) for the quantitative assessment of hepatic steatosis in living donor liver transplantation using histopathology as the standard of reference.

Methods: A total of 21 donors (11 females and 10 males) underwent CT and MRI prior to biopsy. MR IDEAL IQ sequences and CT were performed. Fourty-three biopsies in 21 patients were evaluated by a pathologist by traditional determination of the cell-count fraction. Histopathologically, the presence of steatosis was assessed on a four-point scale $(1=<5 \%, 2=5 \%-10 \%, 3=10 \%-20 \%, 4=>20 \%)$. The relationship between fat fraction and histological grade was analyzed using the Spearman correlation test. To evaluate the diagnostic performance of the parameters, Receiver Operating Characteristics analysis was performed.

Results: Histopathologically, <5\% fat content was found in 12 donors (57\%), 5\%-10\% fat content was found in 4 donors (19\%), 10\%-20\% fat content was found in 3 donors (14\%), and $>20 \%$ fat content was found in 2 donors (10\%). Both MR IDEAL IQ and CT results correlated with the pathological grade $(r=0.736, p=0.005 ; r=0.510, p=0.018$, respectively). MR IDEAL fat fraction results were a better predictor for the evaluation of liver steatosis. MR IDEAL fat fraction sensitivity was $83 \%$.

Conclusion: MR IDEAL sequence for the measurement of liver fat content provides a non-invasive and accurate estimation of the presence and grading of hepatic steatosis.

Keywords: Liver steatosis, magnetic resonance, living donor
\end{abstract}

ORCID ID of the author: O.L.U. 0000-0002-2316-6965; S.B. 0000-0002-0408-6265; A.Ö. 0000-0002-5797-5066; B.K.S. 0000-0002-1470-803X; S.S. 0000-00020779-5999.

\section{INTRODUCTION}

Liver transplantation is divided into two as deceased and living donor liver transplantation (LDLT). Nowadays, LDLT is preferred instead of deceased liver transplantation because of long waiting lists, long duration of ischemia, difficulty of finding a suitable liver, and inability to plan operation (1-3).

The most important ethical problem in LDLT is donor safety because donors encounter both surgical and medical health problems. The pre-transplant radiological preparation of living donors includes the evaluation of the degree of steatosis, hepatic arterial and venous anatomy, bile duct anatomy and variations, focal parenchymal lesions, and volumetric evaluation of the liver. Evaluating steatosis is a critical decision for donor selection because the degree of steatosis is directly proportional to the risk of post-transplant complications in both the recipient and the donor (4).

Non-invasive methods to measure liver steatosis include ultrasonography (US), computed tomography (CT), and magnetic resonance imaging (MRI). US has low sensitivity for detecting low-tomoderate hepatic steatosis (5). The main disadvantage of CT is radiation.

MRI is a very sensitive method in the determination, characterization, and grading of fat in the liver. Chemical shift imaging, rapid spin echo imaging, and MR spectroscopy (MRS) are used in MRI to determine the presence and amount of fat in the liver (6). The aim of the present study was to evaluate hepatic steatosis by taking histopathology as the standard reference in LDLT with MR iterative decomposition of water and fat with echo asymmetry and 
least-squares estimation (IDEAL) sequence and BT densitometer and to compare the diagnostic accuracy of the two methods in determining fatty tissue.

\section{METHODS}

\section{Cases}

This was a retrospective study conducted between September 2016 and February 2018. The study included 21 donors who were donor candidates for liver transplantation and had CT, MRI, and liver biopsy due to hepatic steatosis. Of the 21 donors, 11 (52\%) were female, and 10 (48\%) were male. The mean age of the patients ranged from 23 to $55(37 \pm 8.3)$ years. Patients who did not have sufficient cooperation during the examination, who had claustrophobia, and who had contrast agent allergy were excluded from the study.

Our study was approved by the Ethics Committee of Istanbul Bilim University in accordance with the Declaration of Helsinki.

\section{Image Formation Technique}

Multiphasic abdomen CT (Somatom Sensation 16; Siemens Healthcare, Erlangen, Germany) was applied to all donors with $120 \mathrm{kV}, 350 \mathrm{mAs}$, and $1 \mathrm{~mm}$ collimation parameters. Scanning was made in a triphasic manner; after non-contrast sections, first 140-150 cc, 300-400 mg L/100 mL at a rate of 4-6 mL/s nonionic contrast material, and then $40 \mathrm{~mL}$ normal saline at a rate of 2.5 $\mathrm{mL} / \mathrm{s}$ were injected from the antecubital vein by an automatic injection device.

MR cholangiopancreatography for evaluation of biliary tracts in donors was performed by using MR IDEAL IQ sequence, maximal gradient power of $45 \mathrm{mT} / \mathrm{min}$, and $1.5 \mathrm{~T} \mathrm{MR}$ with op slew rate and value of $200 \mathrm{mT} / \mathrm{m} / \mathrm{ms}$ (Optima MR450w; GE Healthcare, Milwaukee, WI, USA). An 8-channel phased-array body coil was used for examination. IDEAL IO sequence is an oil-water separation method that is T1 independent T2* correction based on chemical shift multiplicity oil spectral modeling. Sequence parameters are detailed in Table 1. The IDEAL IQ sequence produces oil, water, phase-in, non-phase, T2* corrected oil, T2* corrected water, R2* map, and oil fraction map during single breath hold time (21s) (Figure 1. a-f).

\section{Measurement of Hepatic Steatosis}

Hepatic steatosis was calculated by liver attenuation index (LAI). LAI was obtained from unenhanced axial cross-sections of CT by the mean hepatic density measurement of 20 samples with a diameter of $10 \mathrm{~mm}$, which did not have vascular structure in the liver parenchyma, and by subtracting the mean splenic density of the same axial sections. According to this, if $\mathrm{LAl}$ is $>5$, steatosis is $<5 \%$; if $5>\mathrm{LAl}>-10$, steatosis is between $6 \%$ and $30 \%$; and if $\mathrm{LAl}$ is $<-10$, steatosis is $>30 \%$ (7) (Figure $2 a$ ).

Hepatic steatosis was calculated from the fat fraction map with MR IDEAL IQ sequence by taking the mean of three samples from parenchyma areas approximately $10 \mathrm{~mm}$ in diameter from segments II, V, and VIII (Figure 2b).

\section{Donor Biopsy}

Two tru-cut biopsies from each of the 21 liver donors were obtained from liver segment $\mathrm{VI}$ and three from 1 donor. Hepatic steatosis was assessed by the pathologist to determine the cell
Table 1. MR IDEAL IQ sequence parameters

\begin{tabular}{|l|c|}
\hline TR & 17,107 \\
\hline TE & $1,3,3,3,5,3,7,3,9,3,11,3$ \\
\hline FA & $10 \mathrm{~mm}$ \\
\hline ST & $5 \mathrm{~mm}$ \\
\hline SG & $40 \times 28$ \\
\hline FoV & $224 \times 192$ \\
\hline Matrix & 100 \\
\hline Band Width & Yes \\
\hline Breath Holding & $22 \mathrm{~s}$ \\
\hline Inspection Time & \\
\hline TR: time of repetition; TE: time of echo; FoV: field of view, FA: flip angle; SG: \\
slice gap; ST: slice thickness
\end{tabular}

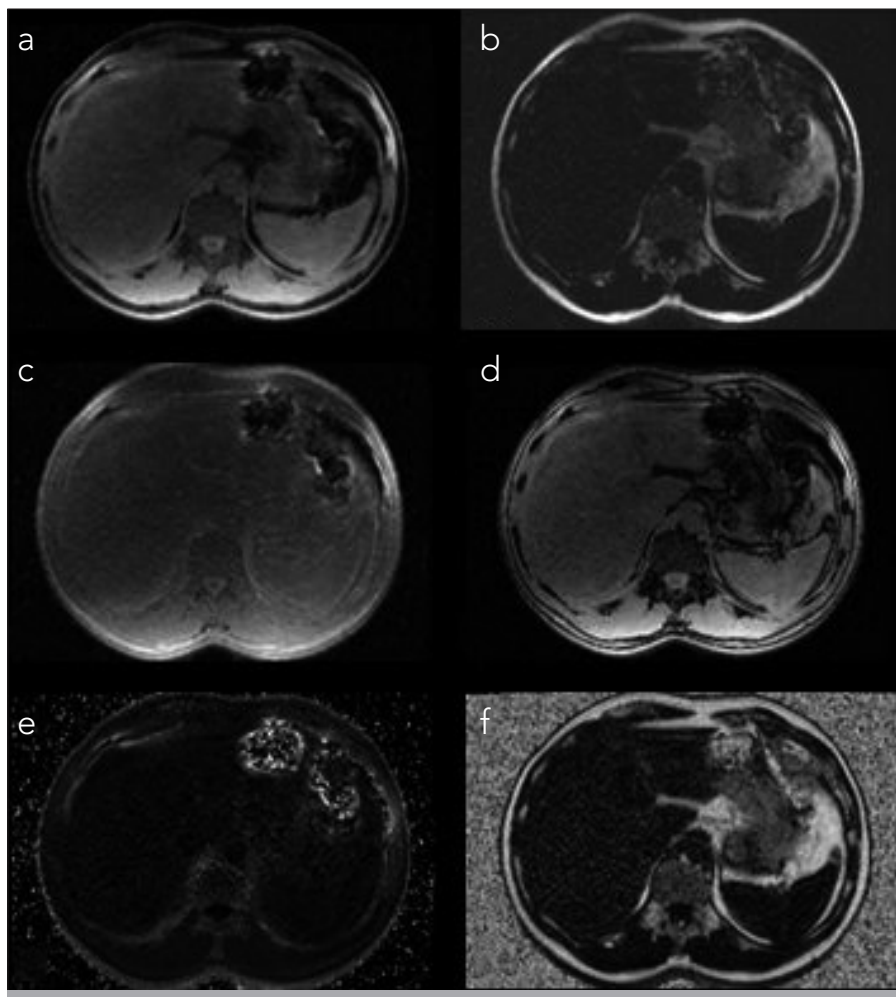

Figure 1. a-f. Maps obtained in the MRIDEAL IQ sequence. (a) Water only, (b) water only, (c) phase-in, (d) non-phase, (e) R2*, and (f) oil fraction maps

count fraction by conventional detection and by a computerbased algorithm.

\section{Statistical Analysis}

Pathologic classification was used as the gold standard. According to this classification, the presence of steatosis was assessed by a four-scaled scale with $1=<5 \%$ fat, $2=5 \%-10 \%$ fat, $3=10 \%-$ $20 \%$ fat, and $4=>20 \%$ fat. The relationship between parameters and histological class was analyzed using the Spearman correlation test. The sensitivity and specificity of MR IDEAL and CT in 


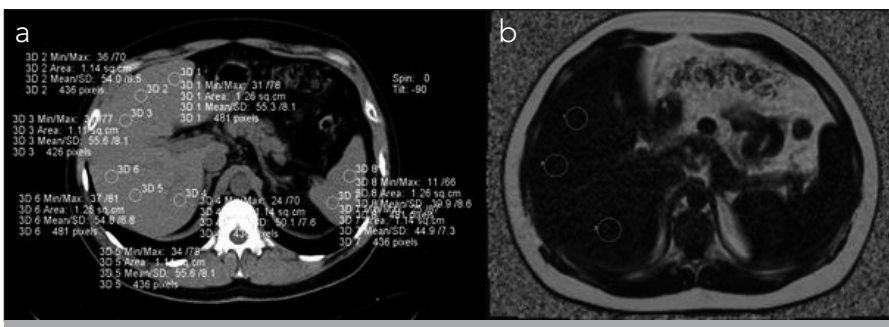

Figure 2. a, b. Measurement of hepatic steatosis. (a) Samples obtained from the liver and spleen in the axial plane image of a CT of at least $10 \mathrm{~mm}$ in diameter used in the calculation of LAl. (b) Examples from segments II, V, and VII of the axial plane from the fat fraction map of the MR IDEAL IQ sequence
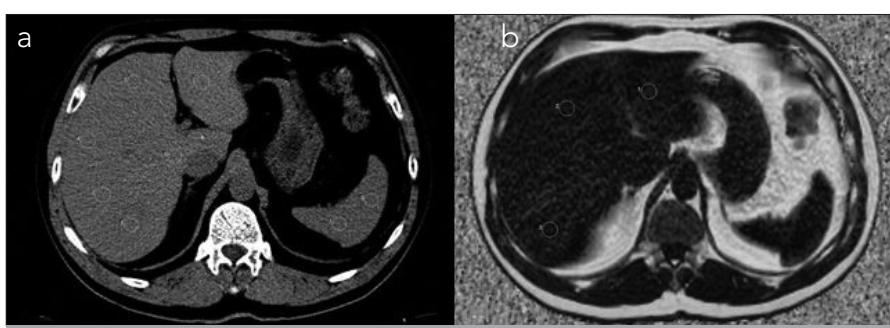

Figure 3. a, b. A 43-year-old male donor liver biopsy result showing $10 \%$ steatosis. (a) $0 \%$ steatosis as a result of BT densitometer, and (b) IDEAL $I Q$ result was $6 \%$ steatosis

determining steatosis were analyzed by receiver operating characteristic (ROC) curve. Data were analyzed by using the Statistical Package for the Social Sciences (SPSS Inc., Chicago, IL, USA).

\section{RESULTS}

According to the histopathological evaluation, of the 21 liver donors, 12 (57\%) had <5\% steatosis, 4 (19\%) had 5\%-10\% steatosis, $3(14 \%)$ had $10 \%-20 \%$ steatosis, and $2(10 \%)$ had $>20 \%$ steatosis.

In the measurement of hepatic steatosis, both MR and CT values were correlated with histopathological grading $(r=0.736, p=0.005$ and $r=0.510, p=0.018$, respectively). When MR IDEAL was compared with CT in evaluating hepatic steatosis, the results of MR IDEAL fat fraction were more correlated with histopathological evaluation. Of the 21 donors, 6 MR IDEAL fat fraction results were found to be closer than BT densitometry (Figure 3a, b).

The best results were obtained with MR IDEAL IQ sequence in the diagnostic evaluation of steatosis. The area under the ROC curve for MR IDEAL IQ sequence was $0.976 \pm 0.078(p=0.002)$, the sensitivity was $83 \%$, and the specificity was $89 \%$. For CT, area under the ROC curve was calculated as $0.866 \pm 0.104(p=0.019)$, sensitivity as $78 \%$, and specificity as $84 \%$.

\section{DISCUSSION}

In LDLT, for a normal person who will give a part of his liver, namely the donor, being healthy after the transplantation is very important. Post-transplant morbidity is reportedly $21 \%$, and mortality is reportedly $0.5 \%$ for the donor in LDLT (8). Hepatic steatosis affects graft function, increases the risk of postoperative complications for the donor, and prevents regeneration of the liver after resection. Therefore, the determination of preoperative hepatic steatosis is essential to reduce the potential complications in donors and to increase the success of the operation.
Although biopsy is the gold standard for detection of hepatic steatosis, it is an invasive technique and has potential morbidity and mortality. It is not practical to repeat the degree of lubrication of donors with liver fatty tissue over time with frequent biopsies. It is not practical to repeat biopsies frequently over time to determine the degree of steatosis in donors with hepatic steatosis (9). The distribution of fat in the liver may not always be homogeneous. Focal steatosis protected fields are common in diffuse steatosis, as well as focal steatosis areas. Ratziu et al. (10) reported an error rate of $24 \%$ due to sampling errors in biopsies.

Previous studies have shown that the lower density of the liver compared with that of the spleen in non-contrast CT detects steatosis in the liver with 88\%-95\% sensitivity and 90\%-99\% specificity $(7,11)$. However, radiation is the biggest disadvantage, and since iron and copper accumulation in the liver and spleen will affect attenuation, values may cause false results.

MRI is currently the most specific imaging modality for the presence of fat in the liver (12). The presence of fat in the liver can be visualized by chemical shift imaging, rapid spin echo imaging, and MRS. Dixon method and the modified Dixon method are advanced techniques based on chemical shift imaging for detecting the presence of fat in the liver.

Proton density fat percentage is calculated by IDEAL IO based on chemical shift imaging $(13,14)$. Hepatic steatosis can be calculated from a large number of regions. Previous studies have shown a good correlation with MRS and liver biopsy, which is the gold standard as in our study (15-17). Kim et al. (15), in their study of 28 obese patients, found that MRS and MR IDEAL sequences are highly correlated with histopathology ( $r=0.954$ and 0.973 , respectively). Idilman et al. (16), in their study of 86 patients with nonalcoholic fatty liver disease, found a very high correlation between MR proton density fat fraction and histopathology $(r=0.82)$. In our study, the MR IDEAL sequence was highly correlated with histopathology $(r=0.736)$.

Our study has some limitations. The most important limitations of the study are the study is retrospective and the low number of donors due to the time between CT, MRI, and biopsy is kept short.

\section{CONCLUSION}

The MR IDEAL IO sequence, which is used to measure liver fat content, calculates the presence and grading of fat in the liver more effectively than CT and non-invasively.

Ethics Committee Approval: Ethics committee approval was received for this study from the Ethics Committee of Istanbul Bilim University School of Medicine.

Informed Consent: Informed consent was not taken from patients due to the retrospective nature of the study.

Peer-review: Externally peer-reviewed.

Author Contributions: Concept - O.L.U,; Design - S.B.; Supervision - S.S., A.Ö.; Resources - S.S., B.K.S.; Materials - S.S.; Data Collection and/or Processing - B.K.S.; Analysis and/or Interpretation - O.L.U., S.B.; Literature Search - S.B.; Writing Manuscript - A.Ö., S.B.; Critical Review - O.L.U., S.B. 
Conflict of Interest: The authors have no conflict of interest to declare.

Financial Disclosure: The authors declared that this study has received no financial support.

\section{REFERENCES}

1. Sterneck M. Indications and general pathology of liver transplantation candidates. In: Bücheler E, Nicolas V, Broelsch CE, Rogiers X, Krupski $G$, editors. Diagnostic and interventional radiology in liver transplantation. Rlin Heidelberg: Springer-Verlag; 2003.p.71-82.

2. Lee SG, Hwang S, Kim KH, Ahn CS, Moon DB, Ha TY, et al. Toward 300 liver transplants a year. Surg Today 2009; 39: 367-73. [CrossRef]

3. Breitenstein S, Apestegui C, Petrowsky H, Clavien PA. State of the art in liver resection and living donor liver transplantation: a worldwide survey of 100 liver centers. Worl J Surg 2009; 33: 797-803. [CrossRef]

4. Chen YS, Cheng YF, De Villa VH, Wang CC, Lin CC, Huang TL, et al. Transplantation 2003; 75(3 Suppl): S16-9. [CrossRef]

5. Strauss S, Gavish E, Gottlieb P, Katsnelson L. Interobserver and intraobserver variability in the sonographic assessment of fatty liver. AJR Am J Roentgenol 2007; 189: W320-3. [CrossRef]

6. Springer F, Machann J, Claussen CD, Schick F, Schwenzer NF. Liver fat content determined by magnetic resonance imaging and spectroscopy. World J Gastroenterol 2010; 16: 1560-6. [CrossRef]

7. Limanond P, Raman SS, Lassman C, Sayre J, Ghobrial RM, Busuttil RW, et al. Macrovesicular hepatic steatosis in living related liver donors: correlation between CT and histologic findings. Radiology 2004; 230: 276-80. [CrossRef]

8. Adam R, McMaster P, O'Grady JG, Castating D, Neuhaus P, Jamiesson $\mathrm{N}$, et al. Evolution of liver transplantation in Europe: report of the European Liver Transplant Registry. Liver Transpl 2003; 9: 1231 43. [CrossRef]
9. Chiang HJ, Lin LH, Li CW, Lin CC, Chiang HW, Huang TL, et al. Magnetic resonance fat quantification in living donör liver transplantation. Transplant Proc 2014; 46: 666-8. [CrossRef]

10. Ratziu V, Charlotte F, Heurtier A, Gombert S, Giral P, Bruckert E, et al. Sampling variability of liver biopsy in nonalcoholic fatty liver disease. Gastroenterelogy 2005; 128: 1898-906. [CrossRef]

11. Park SH, Kim PN, Kim KW, Lee SW, Yoon SE, Park SW, et al. Macrovesicular hepatic steatois in living liver donors: use of CT for quantitative and qualitative assessment. Radiology 2006; 239: 105-12. [CrossRef]

12. Qayyum A, Goh JS, Kakar S, Yeh BM, Merriman RB, Coakley FV. Accuracy of liver fat quantification at MR imaging: comparison of outof-phase gradient-echo and fat saturated fast spin-echo techniques initial experience. Radiology 2005; 237: 507-11. [CrossRef]

13. Yokoo T, Bydder M, Hamilton G, Middleton MS, Gamst AC, Wolfson $T$, et al. Nonalcoholic fatty liver disease: diagnostic and fat-grading accuracy of low-flip-angle multiecho gradient-recalled-echo MR imaging at 1.5 T. Radiology 2009; 251: 67-76. [CrossRef]

14. Reeder SB, Sirlin CB. Quantification of liver fat with magnetic resonance imaging. Magn Reson Imaging Clin N Am 2010; 18: 337-57. [CrossRef]

15. Kim H, Taksali SE, Dufour S, Befroy D, Goodman TR, Petersen KF, et al. Comparative MR study of hepatic fat quantification using singlevoxel proton spectroscopy, two-point dixon and three-point IDEAL. Magn Reson Med 2008; 59: 521-7. [CrossRef]

16. Idilman IS, Aniktar H, Idilman R, Kabacam G, Savas B, Elhan A, et al. Hepatic steatosis: quantification by proton density fat fraction with MR imaging versus liver biopsy. Radiology 2013; 267: 767-75. [CrossRef]

17. Tang A, Tan J, Sun M, Hamilton G, Bydder M, Wolfson T, et al. Nonalcoholic fatty liver disease: MR imaging of liver proton density fat fraction to assess hepatic steatosis. Radiology 2013; 267: 422-31. [CrossRef] 